\title{
Two quality-associated HMW glutenin subunits in a somatic hybrid line between Triticum aestivum and Agropyron elongatum
}

Received: 25 March 2004 / Accepted: 27 August 2004 / Published online: 16 November 2004

(C) Springer-Verlag 2004

\begin{abstract}
High-molecular-weight glutenin subunits (HMW-GSs) from hybrid line II-12 between wheat (Triticum aestivum L.) and Agropyron elongatum (Host) Nivski were characterized with SDS-PAGE. Out of these HMW-GSs, two subunits, h1Bx and h1By, had mobilities similar to the subunits $1 \mathrm{Bx} 13$ and $1 \mathrm{By} 16$ from common wheat 4072, which was used as control. Polyclonal antibodies (pAbs) of h1Bx and h1By were prepared, and Western blotting showed that the pAbs had strong affinities for $\mathrm{h} 1 \mathrm{Bx}$ and $\mathrm{h} 1 \mathrm{By}$, separately. The specificity of h1Bx-pAb was further checked; it preferentially recognized subunits $\mathrm{h} 1 \mathrm{Bx}$ and $1 \mathrm{Bx} 13$. HMW-GS gene coding sequences were amplified by genomic polymerase chain reaction from hybrid II-12. Two of the five amplicons, marked $I I 2 a$ and $I I 3 I b$, were sequenced. Their coding sequences are clustered to Glu-1Bx7 and Glu-1By9 of common wheat. Three discrepant regions in deduced amino acid sequences of $I I 2 a$ and $31 b$ repeated one time more than Glu-1Bx7 and Glu-1By9. N-terminal sequences of $\mathrm{h} 1 \mathrm{Bx}$ and $\mathrm{h} 1 \mathrm{By}$ were determined, which were identical to the published sequences of $1 \mathrm{Bx} 13$ and 1 By16 and in agreement with that deduced from II $2 a$ and $I I 3 I b$, respectively. These results indicated that the two novel genes separated from the hybrid wheat derived from the allelic variation of $1 B x 7$ and $1 B y 9$ of the parent wheat. There is an additional cysteine residue positioned at 271st amino acid of the mature peptide of II2a, which may be related to the high quality of the flour.
\end{abstract}

Communicated by P. Shewry

D. Feng $\cdot$ G. Xia $(\bowtie) \cdot$ S. Zhao $\cdot$ F. Chen

School of Life Sciences,

Shandong University,

Jinan, 250100, China

E-mail: xiagm@sdu.edu.cn

Tel.: + 86-531-8364525

Fax: + 86-531-8565610

\section{Introduction}

The high-molecular-weight glutenin subunits (HMWGSs) encoded by many allelic genes are one class of wheat prolamines. Two linked genes designated as $\mathrm{x}$ - and $\mathrm{y}$-types are located on the long arms of chromosomes 1A, 1B, and 1D. The differences between them are the molecular weight (higher for x-type), number of cysteine residues (four in most x-type subunits, seven in most y-type), and repetitive motifs. Silencing of specific genes results in variation in the number of expressed subunits from three to five, while allelic variation in subunits encoded by the expressed genes leads to polymorphism of x-type and ytype subunits, which can be separated by SDS-PAGE. The association of HMW-GS with bread-making quality has enabled Payne et al. (1981) and Payne and Lawrence (1983) to assign "quality scores" for different alleles. The subunit pair $1 \mathrm{D} \times 5+1 \mathrm{Dy} 10$ is positively associated with bread-making quality compared with subunit pair 1Dx2 + Dy12. The same holds true with the subunit pairs $1 \mathrm{Bx} 17+1 \mathrm{By} 18, \quad 1 \mathrm{Bx} 13+1 \mathrm{By} 16$, and $1 \mathrm{Bx} 14+1 \mathrm{By} 15$ compared with $1 \mathrm{~B} \times 7+1 \mathrm{By} 8, \quad 1 \mathrm{Bx} 7+1 \mathrm{By} 9$, and $1 \mathrm{Bx} 6+1 \mathrm{By} 8$ or $1 \mathrm{Bx} 7$ and the subunits $1 \mathrm{Ax} 1$ or $1 \mathrm{Ax} 2 *$ compared with Null (Mills et al. 2000; Branlard et al. 2001).

Although the HMW-GSs compose around $8-10 \%$ of the total extractable flour protein (Halford et al. 1992), they are present as a network in dough and confer the visco-elastic property, which allows wheat to be processed into bread, pasta, and noodles, as well as a range of other food products. This makes their coding sequences as candidate genes to enhance grain-processing quality through crop genetic transformation (Shewry et al. 2001). Some of HMW-GS genes from wheat (Anderson and Greene 1989; Reddy and Apples 1993) and other related species (Wan et al. 2002; Liu et al. 2003; Feng et al. 2004) have been characterized, but only a few were located on the $\mathrm{B}$ genome.

The immunological method has been increasingly exploited in cereal research (Skerritt and Tatham 1996). 
Polyclonal antibodies (pAbs) were used for detection of a synthetic HMW-GS in the induced cells by Western blotting (Kevin et al. 2001). A monoclonal antibody to a synthetic peptide of HMW-GS 1Dx5 was developed to investigate glutenin polymers (Mills et al. 2000).

Different allelic HMW-GS genes can be transferred via sexual crosses, and hence, different HMW-GS combinations were formed in wheat cultivars. However, only a few reports described the evolutionary origin and allelic variation of HMW-GS (Lawrence and Sheppherd 1981; Thompson et al. 1983; Anderson and Greene 1989; Shewry et al. 1995; Zhang et al. 1997). Some hybrid strains with different quality traits were generated by asymmetric somatic hybridization between wheat (Triticum aestivum L.) Jinan 177 and Agropyron elongatum (Host) Nivski (Xia et al. 2003) and inherited to $\mathrm{F}_{6}$ stably (Chen et al. 2004; Wang et al. 2004). Many "new" HMW-GSs and combinations (absence in either parent) were identified in the hybrid lines (Zhao et al. 2003). These results provided a possibility to understand the allelic variation of HMW-GSs in wheat strains. In this report, we first characterize two quality-associated subunit genes, II2a and II3Ib, from hybrid line II-12. Furthermore, we discuss the possibility of allelic variation from $1 B x 7+1 B y 9$ to $I I 2 a$ and $I I 3 I b$.

\section{Materials and methods}

Plant materials

Agropyron elongatum (Host) Nevski [Thinopyrum ponticum (Podpera) Liu and Wang $2 n=10 x=70$ ], wheat Jinan 177 (T. aestivum L. $2 n=42$ ), Chinese Spring, and hybrid wheat II-12, I-4 which originated from intergeneric somatic hybridization between Jinan 177 and A. elongatum (Xia et al. 2003) and T177 lines derived from tissue cultures of Jinan 177 for $F_{3}$ and $F_{5}$ were stored in our laboratory. Shandong Academy of Agricultural Sciences, Jinan, China, kindly offered seeds of wheat cultivars 4072 and Yanyou 361. Jinan 177, T177, and hybrid lines were all planted in greenhouse separately in order to avoid cross-pollination from other wheat cultivars.

Determination of quality parameters of seed

The seed quality parameters of parent Jinan 177, hybrid II-12 $\mathrm{F}_{3}-\mathrm{F}_{5}$ were determined by Institute of Crop Germplasm Resources, Chinese Academy of Agricultural Sciences, Beijing, China.

\section{SDS-PAGE separation of HMW-GS}

HMW-GSs in the endosperm tissue were extracted from A. elongatum, Jinan 177 (1Dx $2+1 \mathrm{Dy} 12$ and
$1 \mathrm{Bx} 7+1 \mathrm{By} 9)$, T177, hybrid II-12 $\mathrm{F}_{3}-\mathrm{F}_{7}$, Chinese Spring (1Dx2+1Dy12 and 1Bx7+1By8), 4072 (1Ax1, $1 \mathrm{Dx} 5+1 \mathrm{Dy} 10$ and $1 \mathrm{Bx} 13+1 \mathrm{By} 16)$, and Yanyou 361 (1Ax1, 1Dx5+1Dy10 and $1 \mathrm{Bx} 17+1 \mathrm{By} 18)$ with the same method as used by Zhao et al. (2003). SDS-PAGE was according to the procedure described by Feng et al. (2004).

Preparation of pAbs and Western blotting

After electrophoresis, parts of lanes on the gel with identical h1Bx and h1By segments were cut and stained with Coomassie BBG250. The stained lanes were laid back to the original position as markers for excising the $\mathrm{h} 1 \mathrm{Bx}$ and h1By subunits on the other parts of the same unstained gel. The collected h1Bx and h1By subunits were used as antigens to immunize a rabbit. Until appropriate efficiency of antibody was obtained, the serum was collected and used for Western blotting with above HMW-GSs according to Kevin et al. (2001).

\section{Cloning of the ORFs of HMW-GS}

The seeds of hybrid wheat II-12 were grown for 57 days at $25^{\circ} \mathrm{C}$. The extraction of genomic DNA adopted CTAB method according to Murray and Thompson (1980). In order to amplify the complete ORFs of HMW glutenin genes of hybrid II-12 via genomic polymerase chain reaction (PCR), a pair of degenerate primers specific for HMW-GS genes was designed. The sequences of the two primers are P1 (5'ATGGCTAAGCGGC/TTA/GGTCCTCTTTG-3') and P2 (5'-CTATCACTGGCTA/GGCCGA CAATGCG3') (Liu et al. 2003; Feng et al. 2004). A highly fidelity polymerase LA GC Taq (TaKaRa Biotechnology) with a buffer for a GC-rich template was used in PCR in order to reduce the risk of introducing errors into the sequence. The parameters for the reaction were one cycle at $95^{\circ} \mathrm{C}$ for $5 \mathrm{~min}$, followed by 30 cycles of $94^{\circ} \mathrm{C}$ for $40 \mathrm{~s}, 68^{\circ} \mathrm{C}$ for $4 \mathrm{~min}$, and a final extension step at $68^{\circ} \mathrm{C}$ for $10 \mathrm{~min}$. The PCR products were recovered from agarose gels by a gel extraction kit and cloned into pUCm-T vector (Sangon, Shanghai, China) as described previously (Feng et al. 2004). By restrictionenzyme digestion analysis and terminal sequencing, the inserts of two novel clones, pUC II $2 a$ and pUC II3Ib, were deduced to represent the ORFs for the $1 \mathrm{Bx}$ - and 1By-type HMW glutenin subunits respectively. For complete sequencing of the inserts in pUC II $2 a$ and pUC $I I 31 b$, a series of subclones were prepared using the nested deletion method (Sambrook et al. 1989). DNA was sequenced by a commercial company (TaKaRa). The full-length nucleotide sequences of the inserts were assembled from sequencing data from six to eight subclones. For sequence analysis, programs of the NCBI and EBI networks were used. 
Table 1 Quality parameters of Jinan $177(J N$ 177) and hybrid $\mathrm{F}_{3}-\mathrm{F}_{5}$ lines I-4 and II-12. Data are the mean of $\mathrm{F}_{3}-\mathrm{F}_{5}$ results

\begin{tabular}{lllll}
\hline Species & $\begin{array}{l}\text { SDS } \\
\text { sedimentation } \\
(\mathrm{ml})\end{array}$ & $\begin{array}{l}\text { Content of } \\
\text { protein }(\%)\end{array}$ & $\begin{array}{l}\text { Mixing } \\
\text { time } \\
(\mathrm{min})\end{array}$ & $\begin{array}{l}\text { Mixing } \\
\text { tolerance } \\
(\mathrm{min})\end{array}$ \\
\hline I-4 & 35.3 & 16.69 & 3 & $3-5$ \\
JN 177 & 32.5 & 14.48 & 3 & 3 \\
II-12 & 49 & 20.64 & 12 & 16 \\
\hline
\end{tabular}

\section{N-terminal sequences of HMW-GSs}

After SDS-PAGE separation, the HMW-GSs of hybrid II-12 were transferred to a PVDF membrane according to Bryan (1997). Staining of the PVDF membrane with $0.1 \%(\mathrm{~W} / \mathrm{V})$ Coomassie BBR250 and excision of the HMW-GS bands of h1Bx and h1By for protein sequencing were performed in an Applied Biosystems Precise Amino Acid Sequencer by Beijing University, Beijing, China.

\section{Results}

\section{Quality parameters and HMW-GSs}

The flour quality of mixing time and baking performance were tested. Among hybrid $\mathrm{F}_{3}-\mathrm{F}_{5}$ lines of II-12, I-4 and parent wheat, hybrid II-12 was the best. Parts of the quality data are shown in Table 1.

HMW-GSs in the endosperm tissue of Jinan 177, hybrid II-12, A. elongatum, and T177 were preferentially extracted and subjected to SDS-PAGE analysis. Two common wheat cultivars, Chinese spring and 4072, and T177 regenerated from embryo calli of Jinan 177 were used as controls. Jinan 177 showed protein pattern of $2+12$ and $7+9$ (Fig. 1). A. elongatum had more bands than wheat and hybrid, as being a tenfold subspecies. One of the bands had mobility similar to h1By of hybrid (Fig. 1a), while hybrid II-12 from $\mathrm{F}_{3}-\mathrm{F}_{5}$ appeared four fragments different from parent wheat Jinan 177, including $\mathrm{h} 1 \mathrm{Bx}+\mathrm{h} 1 \mathrm{By}$ with mobility similar to subunits 1Bx13 + 1By16 from wheat 4072 (Figs. 1a, 3). T177 lines contained $2+12$ and $7+9$ in most lines. However, a segment substituted the subunit 9, having mobility similar to subunit 8 in a few lines (Fig. 1b).

Homologous detection of $\mathrm{h} 1 \mathrm{Bx}+\mathrm{h} 1 \mathrm{By}$

with $1 \mathrm{Bx} 13+1 \mathrm{By} 16$

After immunizing four times, two pAbs form $\mathrm{h} 1 \mathrm{Bx}$ and h1By with high affinity were obtained. Western blotting with the pAbs displayed strong binding to the subunits $\mathrm{h} 1 \mathrm{Bx}$ and $\mathrm{h} 1 \mathrm{By}$, but weak bindings to other $\mathrm{x}$ - and $\mathrm{y}$ type subunits (Fig. 2). The pAbs' specificity was further checked by immunoblotting different HMW-GSs from cultivars Jinan 177, 4072, Yanyou 361, and somatic hybrid line II-12 between wheat and $A$. elongatum in Western blotting (Fig. 3). The subunit 1Bx 13 from 4072 showed strong signal similar to h1Bx. This indicated that the HMW-GS h1Bx from II-12 was highly homologous to HMW-GS 1Bx13.

\section{Sequences of the ORF of $I I 2 a$ and $I I 3 I b$ genes}

Five DNA fragments were specifically amplified with primer pairs (Fig. 4). They represent different HMW glutenin genes. The fragments of $2.4 \mathrm{~kb}$ marked $I I 2 a$ and $2.2 \mathrm{~kb}$ marked $I I 31 b$ were selected to clone. Partial DNA sequencing indicated that $I I 2 a$ and $I I 3 I b$ inserts represented the ORF of the $\mathrm{x}$ - and y-type of HMW-GS genes, respectively. Using subclones produced by nested deletion, the inserts in pUC II $2 a$ and in pUC $I I 31 b$ were all completely sequenced.

A comparison of the amino acid sequence derived from the II $2 a$ and $I I 31 b$ ORFs to those of published HMW-GSs showed that the primary structure of the II $2 \mathrm{a}$ and II $31 \mathrm{~b}$ subunits were homologous with those of known $\mathrm{x}$ - and y-type subunits respectively. A dendrogram of the relative homologies among the two genes and 22 other published HMW-GS genes from wheat and related species was constructed based on the signal and $\mathrm{N}$-terminal non-repetitive sequences by the Clustal W program of the EBI program net (Table 2; Fig. 5). It

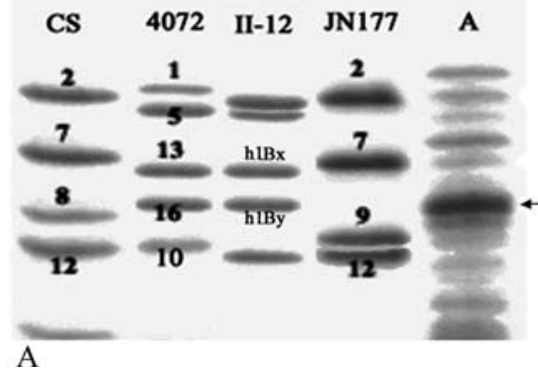

Fig. 1 SDS-PAGE analysis of high-molecular-weight glutenin subunits (HMW-GSs). The HMW subunits in the figure have been marked according to the nomenclature of Payne et al. (1981). a HMW-GS profile from different genotypes of wheat, somatic hybrid, and Agropyron elongatum. b HMW-GS profile

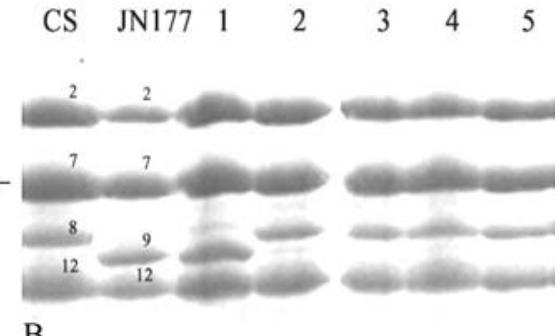

B

from Chinese Spring, Jinan 177 and T177. CS Chinese Spring, 4072 wheat cultivars $4072, I I-12$ hybrid wheat $I I-12$, JN177 Jinan 177, AA. elongatum, lane $1 \mathrm{~T} 177 \mathrm{~F}_{3}$ line with $7+9$ and $2+12$, lane $2 \mathrm{~T} 177 \mathrm{~F}_{3}$ line with $7+8$ and $2+12$, lanes $3-5$ three $\mathrm{F}_{5}$ lines from 2 


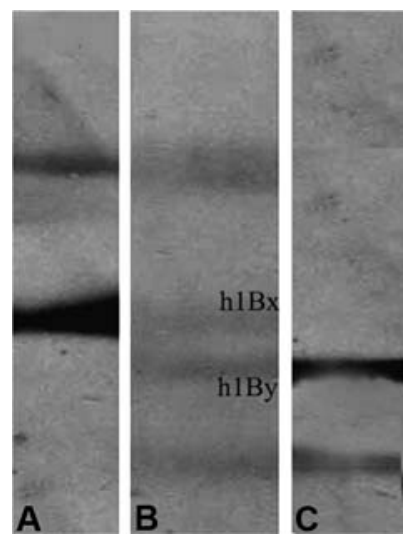

Fig. 2 Western blotting analysis of HMW-GS from hybrid wheat II-12, using pAb affinity to h1Bx (a) and h1By (c) from II2a. b The staining result of a PVDF membrane transferred with the SDS gel containing $\mathrm{h} 1 \mathrm{Bx}$ and h1By

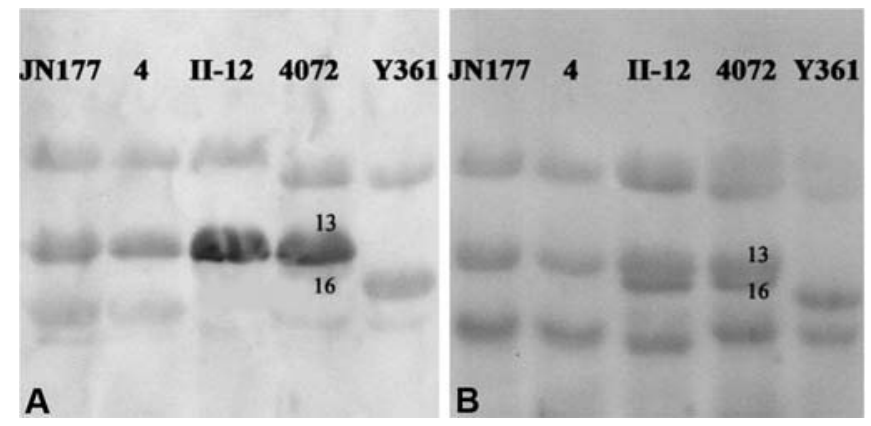

Fig. 3 Western blotting analysis of HMW-GS from various wheat varieties with different HMW-GS composition, using polyclonal antibody affinity to $1 \mathrm{Bx}$ from II2a. a Western blotting result. $\mathbf{b}$ The staining result of a PVDF membrane transferred with the SDS gel containing parent wheat Jinan 177, two hybrid lines between T. aestivum and A. elongatum 4 and II-12, as well as two common wheat cultivars 4072 and Yanyou 361

showed that $I I 2 a$ and $I I 3 I b$ were clustered with Glu$1 B x 7$ and Glu-1By9 respectively. The ORF of the $I I 2 a$ gene, represented by the inset in pUC II $2 a$, consists of 2,391 nucleotides. Its amino acid sequence contained 795 amino acids (Fig. 6). The ORF of the $I I 3 I b$ gene, represented by the inset in pUC $I I 31 b$, consists of 2,220 nucleotides. Its amino acid sequence contained 738 amino acids (Fig. 7). On the basis of the comparison, we can conclude that the primary structures of the two subunits include a signal peptide, an $\mathrm{N}$-terminal region, a central repetitive domain, and a $\mathrm{C}$-terminal region (Figs. 6, 7).

Compared with $1 \mathrm{Bx} 7$, II2a appeared a hexapeptide (PGQGQQ) addition and 22 amino acid residues replaced. In addition, there is a point mutation from A to $\mathrm{G}$, which made the derived amino acid residue at the $271 \mathrm{sh}$ position of the mature peptide change from tyrosine (Y) to cysteine (C) (Fig. 6). Compared with 1By9, there were four hexapeptides (PAQGQQ, PGQGRQ, TRQGQQ, and LEQGQQ), a nonapeptide

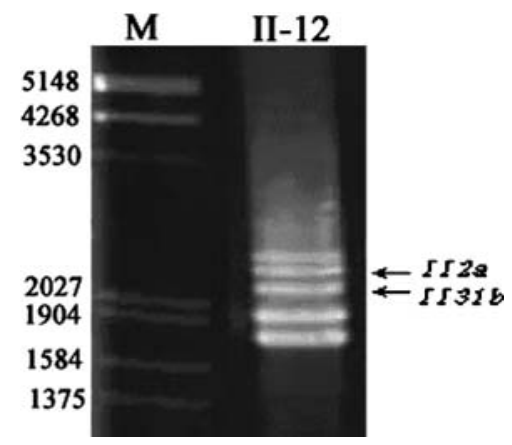

Fig. 4 PCR profile of II-12 DNA amplified with the primer pair. $M$ Marker of EcoRI/HindIII-digested $\lambda$ DNA, II-12 PCR products from hybrid wheat II-12. The II $a$ and $I I 3 I b$ segments are indicated by arrows

(GQYPASQQQ) addition, and 11 amino acid residues replaced in derived amino acid sequence of $I I 3 I b$ (Fig. 7).

Sequences of N-terminal amino acid

The N-terminal sequences of the HMW-GS are compared (Table 3). All the sequences show high degrees of homology. In particular, the N-terminal amino acid sequences $\mathrm{h} 1 \mathrm{Bx}$ and $\mathrm{h} 1 \mathrm{By}$ were identical to $1 \mathrm{Bx} 13$ and 1By16 (Tatham et al. 1991), respectively. The deduced sequences from $I I 2 a$ and $I I 3 I b$ showed a high homology with $1 \mathrm{Bx} 13$ and $1 \mathrm{By} 16$. This revealed that the $\mathrm{h} 1 \mathrm{Bx}$ and h1By are encoded by II2a and $I I 31 b$ genes.

\section{Discussion}

Asymmetric somatic hybridization of common wheat with grass or cereal was successfully used for introgression of alien genome in our lab (Xia and Chen 1996; Xia et al. 2003; Zhou et al. 2001; Xiang et al. 2003; Xu et al. 2003). The hybrid strain II-12 and I-4 from the combination between $T$. aestivum and A. elongatum treated by UV (Xia et al. 2003) inherited from $F_{3}$ to $F_{7}$. II-12 had better quality for bread making than parent wheat and I-4 (Table 1). SDS-PAGE showed that the high quality of the flour was related to the composition of HMWGSs in II-12, which was very different from I-4 $(2+12$, $7+9)$ and parent wheat $(2+12,7+9)$ (Figs. 1a, 3). Two of the HMW-GSs, h1Bx + h1By, in the hybrid were characterized. The comparison of $\mathrm{N}$-terminal amino acid sequencing and Western blotting with specific pAbs revealed that they are homologous with $1 \mathrm{Bx} 13+1 \mathrm{By} 16$ (Fig. 3). Two of the five DNA fragments, III $a$ and $I I 31 b$, amplified by PCR from II-12 were confirmed to be encoding $\mathrm{h} 1 \mathrm{Bx}+\mathrm{h} 1 \mathrm{By}$ by the analysis of sequencing (Figs. 5, 6, 7). Hence, we have cloned two novel HMWGS genes on 1B chromosome from hybrid II-12.

In order to investigate the origin of HMW-GS genes in hybrids, we have cloned five HMW-GS y-type genes from parent grass A. elongatum (Feng et al. 2004; 
Table 2 The information of

high-molecular-weight glutenin subunits $(H M W-G S s)$ in Fig. 5

\begin{tabular}{llll}
\hline HMW-GSs & $\begin{array}{l}\text { The GenBank number } \\
\text { of the coding sequence }\end{array}$ & $\begin{array}{l}\text { The length of the } \\
\text { coding sequence (bp) }\end{array}$ & Species \\
\hline 1Ax1 & X61009 & 2,496 & Triticum aestivum \\
1Dx2 & X03346 & 2,520 & T. aestivum \\
1Dx2t & AF480485 & 2,508 & Agropyron tauschii \\
1Dx2.1t & AF480486 & 2,514 & Aegilops tauschii \\
1Dx5 & X12928 & 2,523 & T. aestivum \\
1Ux & AF476961 & 2,982 & Ae. markgrafii \\
1Cx & AF476959 & 2,391 & Ae. markgrafii \\
R1x & AF216868 & 2,304 & Secale cereal \\
1Bx7 & X13927 & 2,373 & T. aestivum \\
II2a & AY424400 & 2,391 & T. aestivum \\
1Cy & AF476960 & Ae. markgrafii \\
1Ay & X03042 & 1,905 & T. aestivum \\
AgeloG5 & AY319518 & 1,812 & A. elongatum \\
AgeloG6 & AY264065 & 1,515 & A. elongatum \\
AgeloG7 & AY263345 & 1,494 & A. elongatum \\
R1y & AF216869 & 906 & S. cereal \\
1By9 & X61026 & 2,145 & T. aestivum \\
II31b & AY263346 & 2,121 & T. aestivum \\
1Dy12 & X03041 & 2,220 & T. aestivum \\
AgeloG2 & AY263343 & 1,986 & A. elongatum \\
1Dy12t & U39229 & 1,980 & A. tauschii \\
1Dy10 & X12929 & 1,950 & T. aestivum \\
AgeloG3 & AY263344 & 1,950 & A. elongatum \\
1Uy & AF476962 & 1,842 & Ae. umbellulata \\
\hline
\end{tabular}

Fig. 5). Clustering $I I 2 a$ and $I I 3 I b$ sequences and many other HMW-GS genes from wheat cultivars and relatives in GenBank showed that $I I 3 I b$ was more homologous with Glu-1By9 than with all y-type genes of A. elongatum (Fig. 5), although the h1By subunit had a mobility similar with one segment in A. elongatum (Fig. 1a). The $I I 2 a$ was also clustered with $G l u-1 B x 7$ (Fig. 5). Thus, we suggest that the $I I 2 a$ and $I I 31 b$ genes were derived from the allelic variation of $B x 7+B y 9$ genes in Jinan 177.

Till now, over $30 \mathrm{HMW}-\mathrm{GSs}$ and many combinations were detected in a large number of wheat cultivars. Diversity came from sexual crosses between parents with different alleles. No novel allele was created in the strain from normal sexual procedure for wheat-quality breeding. The reason for which is the exact homologous genes crossover in meiosis of sexual hybridization. Allelic variation of wheat HMW-GS via tissue culturing was reported (Larkin et al. 1984; Zhang et al. 1996, 1997; Svec et al. 1999). However, there were no data of sequence verification on these allelic variations as described in this paper. In our experiment, somaclonal variation of HMW-GSs in parent wheat Jinan 177 (T177) was also checked (Fig. 1b); subunit 1By9 was substituted by a new segment having mobility similar to subunit 1By8. But the variation locus (only one) and
Fig. 5 Relative homology of the signal and $\mathrm{N}$-terminal nonrepetitive regions of two genes (II2 $a$ and $I I 31 b$ ) and 22 HMW glutenin genes in common wheat and other related species. The dendrogram is derived from Clustal W program, European Bioinformatics Institute. The GenBank numbers of the genes and the species are listed in Table 2. BoxesII2a and II3Ib

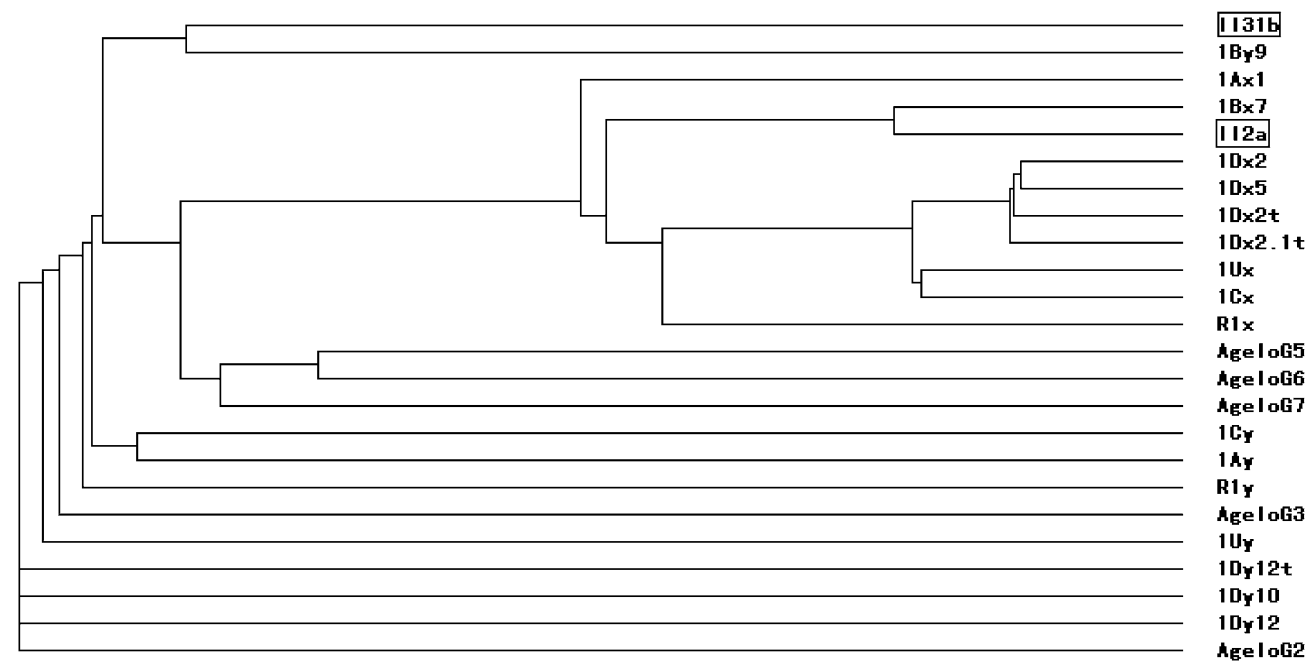


Fig. 6 Comparison of the deduced amino acid sequences of Glu-1Bx7 from common wheat and $I I 2 a$ from the hybrid II-12. Underlining indicates the cysteine residues, boxes contain the signal peptides (21 amino acid residues), Brackets $\mathrm{N}$-terminal region (81 amino acid residues) and C-terminal region (42 amino acid residues), + same amino acid residues in both $1 \mathrm{Bx} 7$ and II2a, - deleted peptide in $1 \mathrm{Bx} 7$

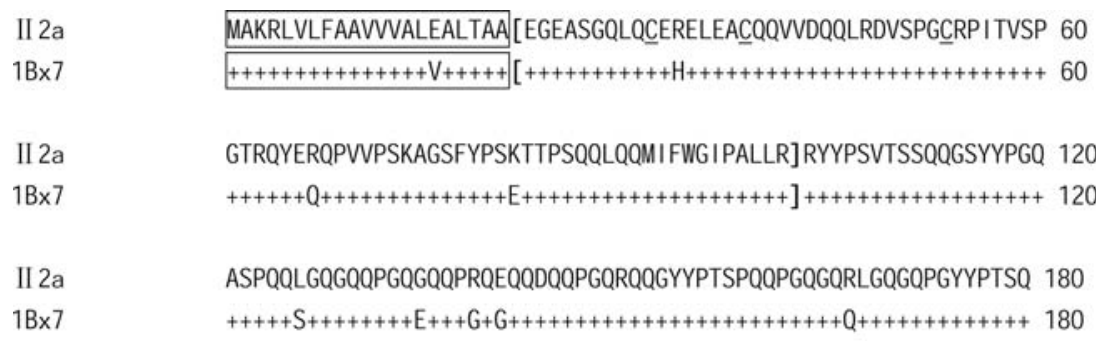

II $2 \mathrm{a}$

$1 \mathrm{~B} \times 7$

II $2 \mathrm{a}$

$1 \mathrm{~B} \times 7$

II $2 \mathrm{a}$

$1 \mathrm{~B} \times 7$

II $2 \mathrm{a}$

$1 \mathrm{~B} \times 7$

II $2 \mathrm{a}$

$1 \mathrm{~B} \times 7$

II $2 \mathrm{a}$

$1 \mathrm{~B} \times 7$

II $2 \mathrm{a}$

$1 \mathrm{~B} \times 7$

II $2 \mathrm{a}$

$1 \mathrm{~B} \times 7$

II $2 \mathrm{a}$

$1 \mathrm{~B} \times 7$
QPGQKQQAGQGQQSGQGQQGYYPTSPQQSGQGQQPGQGQAGYYPTSPQQSGQWQQPGQGQ 240

++++++++++++++++++++++++++++++++++++++++P+++++++++++++++++++++ 240

QPGQGQQSGQGQQGQQPGQGQRPGQGQQGYYPTSPQQPGQGQQSGQGQPGYCPTSLRQPG 300

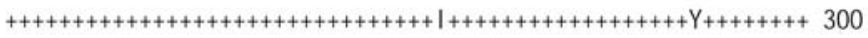

QWQQPGQGQQPGQGQQGQQPGQGQQPGQGQQGYYPTSLQQPGQGQQPGQGQPGYYPTSQQ 360

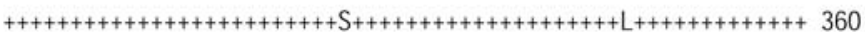

SEQGQQPGQGKQPGQGQQGYYPTSSQQSGQGQQLGQGQPGYYPTSPQQSGQGQQSGQGQQ 420

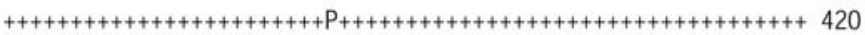

GYYPTSPQQSGQGQQPGQGQSGYFPTSRQQSGQGQQPGQGQQSGQGQQGQQPGQGQQAYY 480

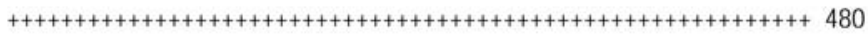

PTSSQQSGQRQQAGQWQRPGQGQSGYYPTSPQQPGQEQQSGQAQQSGQWQLVYYPTSPQQ 540

++++++++R++++++++++++++++P++++++++++++++++++++++++++++++++++++++++ 540

PGQLQQPAQGQQPAQGQQSAQEQQPGQAQQSGQWQLVYYPTSPQQPGQLQQPAQGQQGYY 600

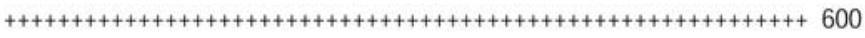

PTSPQQSGQGQQGYYPTYPQQSGQGQQGYYPTSPQQSGQGQQPGQGQQPRQGQQGYYPIS 660

++++++++++++++++++S++++++++++++++++++++++++++++++++++++++++++++++ 660

PQQSGQGQQPGQGQQGYYPTSPQQSGQGQQPGHEQQPGQWLQPGQGQQGYYPTSSQQSGQ 720 frequency (about 10\%) were much lower than in the somatic hybrid strains (Zhao et al. 2003). Although these genes have not been sequenced completely, it is suggested that most of them originated from allelic variation of Null, $1 \mathrm{Bx} 7+1 \mathrm{By} 9$, and $1 \mathrm{Dx} 2+1 \mathrm{Dy} 12$ of Jinan 177, based on this experiment. Heritable allelic variation of HMW-GSs has been verified in the II-12 $\mathrm{F}_{3}-\mathrm{F}_{7}$ self-bred line ( $\mathrm{Z}$. Liu et al, personal communication). In the process of hybridization, many factors were involved in the genome variation and resulted in unequal crossover of homologous genes-for example, somaclonal variation in the parent and hybrid tissue culture, isolation and regeneration of cell wall of the protoplasts and fusion cells, UV treatment to the donor protoplast, the interaction and exclusion of parent genome, and the genetic unbalance, etc. We conclude that asymmetric somatic hybridization could not only introduce alien nuclear/cytoplasm genes (Wang et al. 2003) but also lead to allelic variation of HMW-GSs with high frequency. This technology can provide many novel strains for the quality improvement of wheat and for the study of allele-variation rule of HMW-GS genes.

We can deduce that this "mutation" likely derived from unequal crossover or slip mismatching during meiosis in homologous chromosomes and/or unequal crossing-over during mitosis in sister chromosomes. It was suggested that the evolutionary origin of HMWGSs involved a same ancestor (Lawrence and Sheppherd 1981; Thompson et al. 1983; Anderson and Greene 1989; Shewry et al. 1995). Many kinds of HMW-GSs and combinations in the asymmetric somatic hybrid lines of wheat with $A$. elongatum (Zhao et al. 2003) likely reflect evolution process of HMW-GSs - a compressed "episode" of evolution from a single ancestral gene.

Biophysical studies have shown that the individual subunits have an extended rod-like shape, resulting from the central repetitive domain, which forms a loose spiral structure (Miles et al. 1991). The interactions (disulfide 
Fig. 7 Comparison of the deduced amino acid sequences of $\mathrm{Glu}-1 \mathrm{By} 9$ from common wheat and $I I 31 \mathrm{~b}$ gene from the hybrid II-12. Underlining indicates the cysteine residues, boxes contain signal peptides, Brackets $\mathrm{N}$-terminal region (104 amino acid residues) and C-terminal region (42 amino acid residues), + same amino acid residues in 1 By 9 and II $31 \mathrm{~b}$; - deleted peptide in 1 By 9

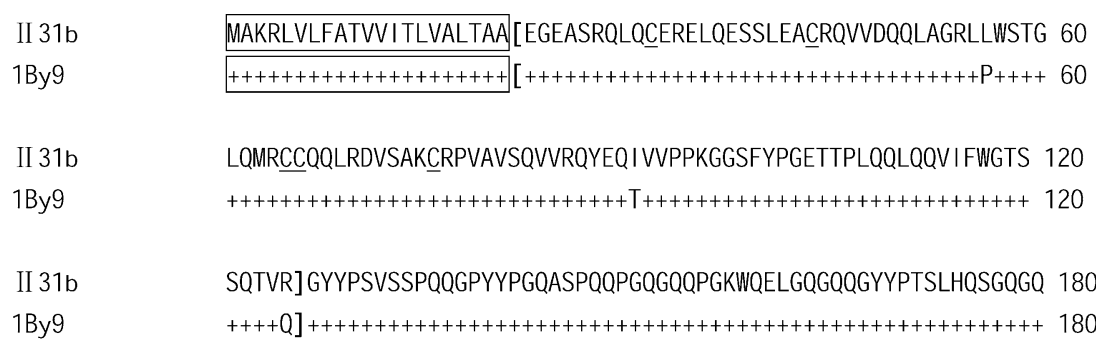

II 31b

1 By 9

II $31 \mathrm{~b}$

1 By9

II $31 \mathrm{~b}$

1 By 9

II 31b

1 By 9

II $31 \mathrm{~b}$

1 By 9

II $31 \mathrm{~b}$

1 By 9

II 31b

1 By 9

II $31 \mathrm{~b}$

1 By9

II $31 \mathrm{~b}$

1 By 9

II $31 \mathrm{~b}$

1 By9
QGYYPSSLQQPGQGQQTGQGQQGYYPTSLQQPGQGQQI GQGQQGYYPTSPQHPGQRQQPG 240

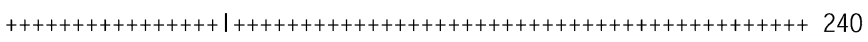

QGQQIGQGQQLGQGRQIGQGQQSGQGQQGYYPTSPQQLGQGQQPGQWQQSGQGQQGYYPT 300

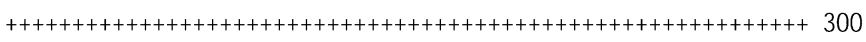

SQQQPGQGQQGQYPASQQQPGQGQQGQYPASQQQPGQGQQGQYPASQQQPAQGQQGQYPA 360

+++++++++++++++++++++++++++++++++++++++++++++++++++++++----------- 349

SQQQPGQGQQGHYLASQQQPGQGQQRHYPASLQQPGQGQQGHYTASLQQPGQGQQGHYPA 420

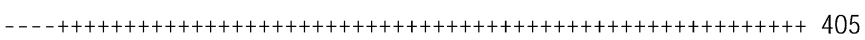

SLQQVGQGQQI GQLGQRQQPGQGRQTRQGQQLEQGQQPGQGQQTRQGQQLEQGQQPGQGQ 480

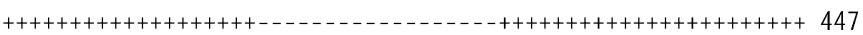

QTRQGQQLEQGQQPGQGQQGYYPTSPQQSGQGQQPGQSQQPGQGQQGYYSTSLQQPGQGQ 540

+++++++++++++++++++++++++++++++++++++++++++++++++++++++++S+++++++++ $\mathrm{L} 507$

QGHYPASLQQPGQGHPGQRQQPGQGQQPKQGRQPGQGQQGYYPTSSQQPGQGKQLGQGQQ 600

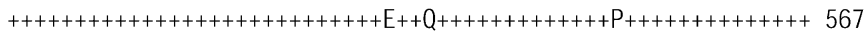

GYYPTSPQQPGQGQQPGQGQQGHCPTSPQQTGQAQQPGQGQQ I GQVQEPGQGQQGYYPIS 660

+++++++++++++++++++++++++++++++++++++++++++++++++++++Q

LQQSGQGQQSGQGQQSGQGHQLGQGQRSGQEQQGYD[NPYHVNTEQQTASPKVAKVQQPAT 720

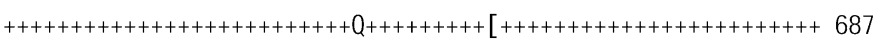

QLPIMCRMEGGDALSASQ] 738

++++++++++++++++++++] 705

Table 3 Comparison of derived N-terminal amino acid sequences of II2a, II31b, HMW-GSs h1Bx and h1By from hybrid wheat II-12, and $1 \mathrm{Bx} 13$ and $1 \mathrm{By} 16$ from bread wheat

\begin{tabular}{|c|c|c|}
\hline Subunit & Residues & Reference \\
\hline *h1Bx & EGEASGQLQCEREL & This paper \\
\hline * $1 \mathrm{~B} \times 13$ & EGEASGQLQCERELEACQQVVDQQLRDVSPGCRXIXVS & (Tatham et al. 1991) \\
\hline${ }^{* *} \mid 12 \mathrm{a}$ & EGEASGQLQCERELEACQQVVDQQLRDVSPGCRPITVS & This paper \\
\hline *h1By & EGEASRQLQCERELQ & This paper \\
\hline *1By16 & EGEASRQLQCERELQESSLEACRQVVDQQLAGRLPWSTGLQMRCCXXL & (Tatham et al. 1991) \\
\hline${ }^{* *}|| 31 b$ & EGEASRQLQCERELQESSLEACRQVVDQQLAGRLLWSTGLQMRCCQQL & This paper \\
\hline
\end{tabular}


cross-linking and hydrogen bonding) between subunits contribute to flour elastic property (Shewry et al. 1992). An extra cysteine residue $\left(\mathrm{Cys}^{97}\right)$ at the beginning of the repetitive domain of $1 \mathrm{Dx} 5$ subunit had a positive influence on dough properties (Lafiandra et al. 1993), whereas $1 \mathrm{Bx} 20$ has a detrimental effect on dough strength when it was compared with subunit $1 \mathrm{Bx} 7$. The major difference between them was the substitution of two cysteine residues in the $\mathrm{N}$-terminal domain of subunit $1 \mathrm{Bx} 20$ by two tyrosine residues (Shewry et al. 2003). The impact of additional cysteine residue $\left(\mathrm{Cys}^{271}\right)$ in the repetitive domain of h1Bx subunit (Fig. 6) on dough quality is needed to study.

Acknowledgements The National Natural Science Foundation of China, no. 30370857, Major Project of Ministry of Education in China and National 863 High Technology Research and Development Project no. 2001AA241032 supported this study.

\section{References}

Anderson OD, Greene FC (1989) The characterization and comparative analysis of high molecular weight glutenin genes from genomes $\mathrm{A}$ and $\mathrm{B}$ of a hexaploid bread wheat. Theor Appl Genet 77:689-700

Branlard G, Dardevet M, Saccomano R, Lagoutte FL, Gourdon J (2001) Genetic diversity of wheat proteins and bread wheat quality. Euphytica 119:59-67

Bryan JS (1997) Protein sequencing protocols: methods in molecular biology, vol 64. Humana, Totowa

Chen SY, Liu SW, Cheng YZ, Xia GM (2004) Heredity of chloroplast and nuclear genomes of asymmetric somatic hybrid lines between wheat and couch grass. Acta Bot Sin 46:110-115

Feng DS, Chen FG, Zhao SY, Xia GM (2004) High-molecularweight glutenin subunit genes in decaploid Agropyron elongatum. Acta Bot Sin 46:489-496

Halford NG, Field JM, Blair H, Urwin P, Moore K, Robert L, Thompson RD, Flavell RN, Tatham AS, Shewry PR (1992) Analysis of HMW glutenin subunits encoded by chromosome $1 \mathrm{~A}$ of bread wheat (Triticum aestivum L.) indicates quantative effects on grain quality. Theor Appl Genet 83:373-378

Kevin AF, Tatham AS, Gilbert SM, Fido RJ, Halford NG, Shewry PR (2001) Synthesis, expression and characterization of peptides comprised of perfect repeat motifs based on a wheat seed storage protein. Biochim Biophys Acta 1546:346355

Lafiandra D, D'Ovidio R, Porceddu E, Margiotta B, Colaprico G (1993) New data supporting high $M_{\mathrm{r}}$ glutenin subunit 5 as the determinant of quality differences among the pairs $5+10$ vs 2+12. J Cereal Sci 18:197-205

Larkin PJ, Ryan S, Brettel J, Scowcroft W (1984) Heritable somaclonal variation in wheat. Theor Appl Genet 67:443-451

Lawrence GJ, Sheppherd KW (1981) Chromosome location of genes controlling seed proteins in species related to wheat. Theor Appl Genet 59:25-31

Liu Z, Yan Z, Wan Y, Liu K, Zheng Y, Wang D (2003) Analysis of HMW glutenin subunits and their coding sequences in two diploid Aegilops species. Theor Appl Genet 106:1368-1378

Miles M, Carr HJ, McMaster T, Belton PS, Morris VJ, Field JM, Shewry PR, Tatham AS (1991) Scanning tunneling microscopy of a wheat seed storage protein reveals details of an unusual supersecondary structure. Proc Natl Acad Sci USA 88:68-71

Mills ENC, Field JM, Kauffman JA, Tatham AS, Shewry PR, Morgan MRA (2000) Characterization of monoclonal antibody specific for HMW subunits of glutenin and its use to investigate glutenin polymers. J Agric Food Chem 48:611-617
Murray MG, Thompson WF (1980) The isolation of high molecular weight plant DNA. Nucleic Acids Res 8:4321-4325

Payne PI, Lawrence GD (1983) Catalogue of alleles for the complex gene loci, Glu-B1 and Glu-D1 which code for high molecular weight subunits of glutenin in hexaploid wheat. Cereal Res Commun 11:29-35

Payne PI, Corfied KG, Hoft LM, Blackman JA (1981) Correlations between the inheritance of certain high molecular weight glutenin subunits of glutinen and breadmaking quality in the progeny of six crosses of wheat bread. J Sci Food Agric 32:51-60

Reddy P, Apples R (1993) Analysis of a genomic DNA segment carrying the wheat high molecular weight (HMW) glutenin Bx17 subunit and its use as an RFLP marker. Theor Appl Genet 85:616-624

Sambrook J, Fritsch EF, Maniatis T (1989) Molecular cloning: a laboratory manual. Cold Spring Harbor Laboratory Press, Cold Spring Harbor

Shewry PR, Halford NG, Tatham AS (1992) High molecular weight subunits of wheat glutenin. J Cereal Sci 15:105-120

Shewry PR, Napier JA, Tatham AS (1995) Seed storage proteins: structure and biosynthesis. Plant Cell 7:945-956

Shewry PR, Tatham AS, Fido R, Jones H, Barcelo P, Lazzeri PA (2001) Improving the end use properties of wheat by manipulating the grain protein composition. Euphytica 119:45-48

Shewry PR, Gilbert SM, Savage AWJ, Tatham AS, Wan YF, Belton PS, Wellner N, D'Ovidio R, Bekes F, Halford NG (2003) Sequence and properties of HMW subunit $1 \mathrm{Bx} 20$ from pasta wheat (Triticum durum) which is associated with poor end use properties. Theor Appl Genet 106:744-750

Skerritt JH, Tatham AS (1996) Cereal seed storage proteins. In Van Regenmortel MHV (ed) Structure of antigens, vol 3. CRC, Boca Raton, pp 349-386

Svec M, Gregova E, Miklovicova M, Kraic J (1999) Short communication change in expression of HMW glutenins of wheat (Triticum aetivumm L.) induced by nitrosoethylurea. Plant Breed 118:272

Tatham AS, Field JM, Keen JN, Jackson PJ (1991) Purification and characterization of HMW glutenin subunits encoded by chromosome 1B of durum wheat (Triticum durum). J Cereal Sci 14:111-116

Thompson RD, Bartels D, Harberd NP, Flavell RB (1983) Characterization of the multigene family coding for HMW glutenin subunits in wheat using cDNA clones. Theor Appl Genet 67:87-96

Wan YF, Wang DW, Shewry PR, Halford NG (2002) Isolation and characterization of five novel high molecular weight subunit of glutenin genes from Triticum timopheevi and Aegilops cylindrical. Theor Appl Genet 104:828-839

Wang YP, Sonntag K, Rudloff E (2003) Development of rapeseed with high erucic acid content by asymmetric somatic hybridization between Brassica napus and Granba sbyssinica. Theor Appl Genet 106:1147-1155

Wang J, Xiang F, Xia G (2004) Transfer of small chromosome fragments of Agropyron elongatum to wheat chromosome via asymmetric somatic hybridization. Sci China Ser C, 34(1) (in press)

Xia GM, Chen HM (1996) Plant regeneration from intergeneric somatic hybridization between Triticum aestivum L. and Leymus Chinensis (trin.) Tzvel. Plant Sci 120:197-203

Xia GM, Xiang FN, Zhou AF, Wang H, He SX, Chen HM (2003) Asymmetric somatic hybridization between wheat (Triticum aestivum L.) and Agropyron elongatum (Host) Nevski. Theor Appl Genet 107:299-305

Xiang FN, Xia GM, Chen HM (2003) Effect of UV dosage on somatic hybridization between common wheat (Triticum aestivum L.) and Avena sativa L. Plant Sci 164:697-707

Xu CH, Xia GM, Zhi DY, Xiang FN, Chen HM (2003) Integration of maize nuclear and mitochondrial DNA into the wheat genome through somatic hybridization. Plant Sci 165:1001-1008

Zhang HG, Chen JX, Zhao XL, Hu H (1996) HMW-GS variation of somaclones and its variants in Triticum aestivum. Chin Sci Bull 41:330-334 
Zhang HG, Chen JX, Hu H (1997) Genetic analysis of Glu-1 somaclonal mutant in wheat (in Chinese with English Abstract). Hereditas (Beijing) 19:23-25

Zhao TJ, Qua TY, Xia GM, Chen HM (2003) Glutenin and SDS sedimentation analysis of the F5 somatic hybrids between Triticum aestivum L. and Agropyron elongatum (in Chinese with English Abstract). J Shandong Univ (Nat Sci) 38(3):112-116
Zhou A, Xia G, Zhang X, Chen H, Hu H (2001) Analysis of chromosomal and organellar DNA of somatic hybrids between Triticum aestivum and Haynaldia Villosa Schur. Mol Genet Genomics 265:387-393 